\title{
MODELAGEM COMO FERRAMENTA PARA AVALIAÇÃO DO IMPACTO DE DERRAMAMENTOS DE GASOLINA COM ETANOL NA ZONA VADOSA
}

\author{
Marilia Offemann Skowronski ${ }^{1}$; Henry Xavier Corseuil ${ }^{2}$ \& Nilson Guiguer $\mathrm{Jr}^{3}$
}

\begin{abstract}
Resumo - O aumento mundial da utilização do etanol como combustível puro ou misturado com a gasolina tem causado preocupações quanto aos possíveis impactos que possam ser causados em casos de derramamentos. Um dos pontos críticos debatidos está associado à infiltração e distribuição do etanol na subsuperfície. Um experimento de campo com a liberação de $200 \mathrm{~L}$ de uma mistura contendo $85 \%(\mathrm{v} / \mathrm{v})$ de etanol e $15 \%(\mathrm{v} / \mathrm{v})$ de gasolina (E85) na zona não saturada à 1,60 $\mathrm{m}$ do nível freático foi realizado em Florianópolis com o objetivo de investigar a transferência de etanol na zona vadosa em região com elevados índices pluviométricos e variação do nível da água. Neste trabalho será utilizada a modelagem, através do modelo FEFLOW, a fim de avaliar os impactos deste derramamento na zona vadosa.
\end{abstract}

Palavras-Chave - Zona vadosa, modelagem, etanol.

Abstract - The increased use of ethanol as pure fuel or blended with gasoline has been causing concerns regarding possible impacts in case of spills. One of the most discussed points is associated with the infiltration of ethanol and its subsurface distribution. A field experiment with the controlled release of $200 \mathrm{~L}$ of a mixture containing $85 \%(\mathrm{v} / \mathrm{v})$ ethanol and $15 \%(\mathrm{v} / \mathrm{v})$ gasoline (E85) in the unsaturated zone, $1.60 \mathrm{~m}$ above water table, was performed in Florianopolis in order to investigate ethanol transfer to the vadose zone, in a region with high rainfall and water table fluctuations. In this work will be used FEFLOW model to evaluate the impacts of this spill in the vadose zone .

Keywords - Vadose zone, modeling, ethanol.

\footnotetext{
${ }^{1}$ Universidade Federal de Santa Catarina - UFSC, Centro Tecnológico - CTC, Departamento de Engenharia Sanitária e Ambiental, Laboratório REMA. Florianópolis/SC. CEP: 88040-900. Fone: (48) 3721- 2132

${ }^{2}$ E-mail: mariliaesa@ hotmail.com

${ }^{3}$ E-mail: henry.corseuil@ufsc.br

${ }^{4}$ E-mail: nguiguer@hotmail.com
} 


\section{1 - INTRODUÇÃO}

A importância das águas subterrâneas como uma das principais fontes de abastecimento de água potável justifica a preocupação com a preservação da subsuperfície e a busca de alternativas para a minimização de impactos provenientes de compostos potencialmente poluidores. No Estado de São Paulo, por exemplo, aproximadamente $80 \%$ dos municípios são total ou parcialmente abastecidos por águas subterrâneas (CETESB, 2014), porém há uma crescente contaminação das águas subterrâneas ocasionada, por exemplo, por agrotóxicos, fossas sépticas, aterros sanitários, salinidade e derramamentos de combustíveis e biocombustíveis.

No Brasil, desde 1975 com o programa Proálcool, o biocombustível etanol, que é um agente oxigenante, vem sendo adicionado à gasolina para aumentar sua octanagem, porém no início do programa o principal objetivo de acrescentar o etanol à gasolina era de minimizar os custos, já que havia a crise mundial do petróleo ocasionada pela Organização dos Países Exportadores de Petróleo (OPEP). Desde março de 2015, a porcentagem de etanol na gasolina comum é de $27 \%$ e na gasolina premium é de $25 \%$, segundo a Portaria $\mathrm{N}^{\circ} 75$ do Ministério da Agricultura, Pecuária e Abastecimento, Resolução $\mathrm{N}^{\circ} 1$ do Conselho Interministerial do Açúcar e do Álcool e Decisão $\mathrm{N}^{\circ}$ 20 da Secretaria de Desenvolvimento Agropecuário e Cooperativismo.

O comportamento do etanol em subsuperfície tem sido estudado, devido à porcentagem deste na gasolina comercial brasileira e também à sua grande utilização como combustível, o que aumenta a chance de que ocorram diferentes proporções de gasolina e etanol na subsuperfície em casos de derramamentos.

O fluxo através da zona vadosa é uma parte importante do ciclo hidrológico, devido às influências do particionamento de água entre os vários fluxos componentes. Dependendo das características hidrológicas, geológicas, e do solo, a chuva e neve derretida são divididas na superfície da terra em segundo turno, infiltração, evapotranspiração, as águas subterrâneas, recarga e armazenamento de zona vadosa. A modelagem de processos na zona vadosa é uma tarefa complexa e exigente em termos computacionais que é muitas vezes prejudicada pela falta de dados necessários para caracterizar as propriedades hidráulicas do ambiente da subsuperfície. Consequentemente, os processos de fluxo na zona vadosa têm sido raramente representados de forma devida em modelos hidrológicos (TWARAKAVI et. al 2008).

Neste estudo será utilizado o modelo FEFLOW (Finite Element Subsurface Flow \& Transport Simulation System), o qual utiliza a técnica numérica de elementos finitos para simular tanto o fluxo como o transporte de poluentes. Executa simulações bi ou tridimensionais, estacionárias ou transientes, podendo englobar os processos que ocorrem tanto na zona saturada 
como na não saturada, além de considerar os efeitos da temperatura e da salinidade no transporte (FAGUNDES, 2010).

A motivação deste trabalho foi demonstrar a aplicação de um modelo para avaliar os impactos gerados por um derramamento de gasolina com etanol na zona vadosa, visto que se encontram poucos trabalhos técnicos que ilustrem e exemplifiquem a utilização de modelos para cenários de contaminação por combustíveis no ambiente subterrâneo.

\section{2 - OBJETIVOS}

\section{1 - Objetivo Geral}

O objetivo geral deste trabalho foi avaliar o comportamento da migração do etanol na zona vadosa, em uma mistura de combustíveis contendo gasolina, por meio da utilização do modelo FEFLOW.

\section{2 - Objetivos Específicos}

a) Analisar a influência da precipitação nas flutuações do nível do lençol freático, e consequentemente no transporte de etanol na zona vadosa;

b) Avaliar o particionamento do etanol na zona vadosa em função da umidade do solo;

c) Identificar as consequências do comportamento do etanol no transporte de hidrocarbonetos da gasolina na zona insaturada;

d) Comparar os resultados de campo com os obtidos pelo modelo FEFLOW.

\section{3 - MODELAGEM NA ZONA VADOSA}

Para aplicações em escalas maiores são utilizados modelos distribuídos, ou seja, modelos que respondem por variações espaciais de variáveis e parâmetros. Estes modelos podem ser subdivididos em modelos de unidades hidrológicas, os quais são discretizados em subbacias, ou em unidades menores, com base em características físicas semelhantes, como geomorfológicas e hidráulicas. Nessas unidades, a zona vadosa é representada por submodelos 1D ou 2D. Outras abordagens também são consideradas como os modelos de águas subterrâneas de superfície 3D e descrição do fluxo preferencial na zona vadosa. Idealmente, todos os submodelos estão totalmente acoplados por condições de contorno apropriadas (Figura 1) (KOHNE et. al, 2009). 


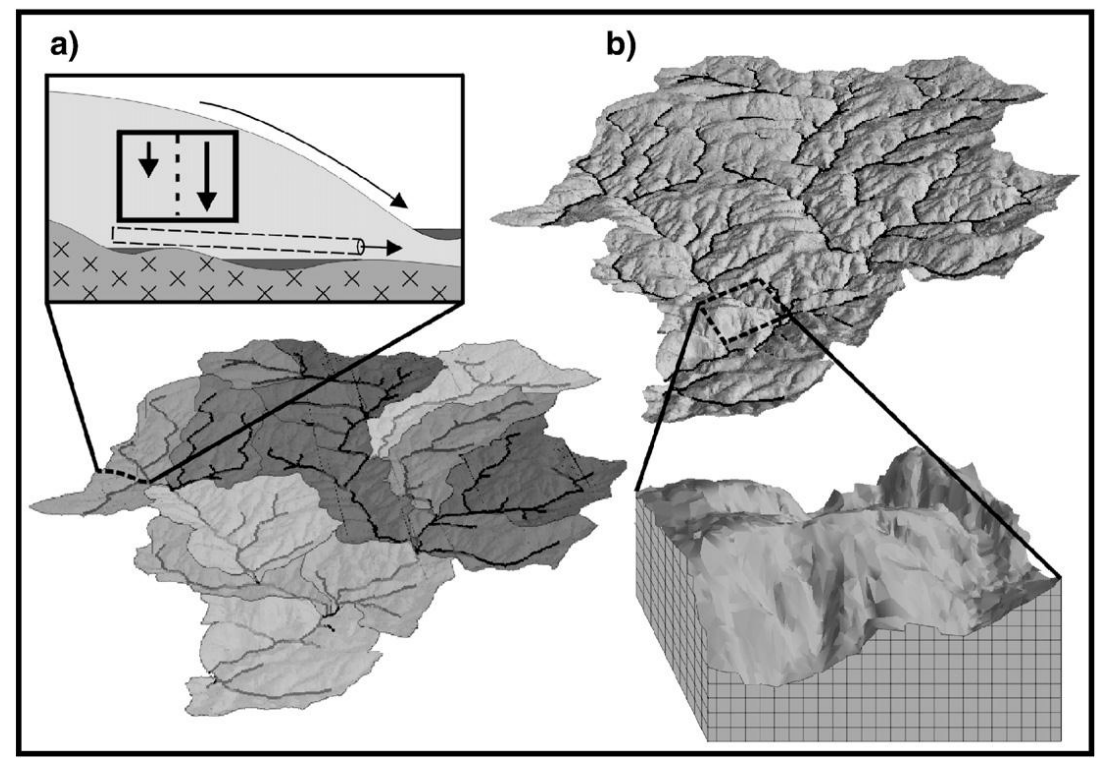

Figura 1 - Modelos distribuídos. a) Modelos de unidade hidrológica b) superfície 3D/zona vadosa/modelos de águas subterrâneas. Fonte: KOHNE et. al (2009).

\section{1 - Modelo FEFLOW}

O modelo matemático FEFLOW (Finite Element Subsurface Flow \& Transport Simulation System) desenvolvido pela WASY Institute for Water Resources Planning and Systems Research, Berlim, Alemanha, constitui um software sofisticado que entra em linha de conta com estas características. Consiste num modelo interativo de simulação em 3D e 2D do fluxo subterrâneo variável em função da densidade e dos processos de transporte de massa e de calor nas águas subterrâneas, utilizando o método numérico de resolução das equações diferenciais parciais por elementos finitos.

Este software traduz-se numa ferramenta eficiente para a modelação das águas subterrâneas que permite, entre muitos outros aspectos: (1) a modelação de sistemas subterrâneos que se caracterizem pela existência (ou não) de superfícies livres, como é o caso de aquíferos freáticos, e aquíferos suspensos, implementando uma aproximação que permite a movimentação dos elementos da malha; (2) a solução de problemas nas zonas saturada e vadosa do solo; (3) a modelação de fenômenos de transporte variável em função simultânea das densidades e da temperatura; (4) o transporte de contaminantes por convecção e por dispersão, no qual as espécies químicas podem estar sujeitas a adsorção, dispersão hidrodinâmica e reações químicas de $1^{\text {a }}$ ordem (DIAMANTINO; FERREIRA, 2002). 


\section{4 - MATERIAIS E MÉTODOS}

Para realizar este trabalho serão reunidas informações hidrogeológicas da àrea de estudo, as quais serão obtidas, em sua maioria, a partir de estudos já realizados na área em questão. Através destes dados será elaborado um modelo conceitual hidrogeológico para a área, que será utilizado no modelo FEFLOW 6.2 da DHI -WASY a fim de simular o comportamento dos contaminantes na zona vadosa. O desenvolvimento desta pesquisa se dará conforme o fluxograma da Figura 2.

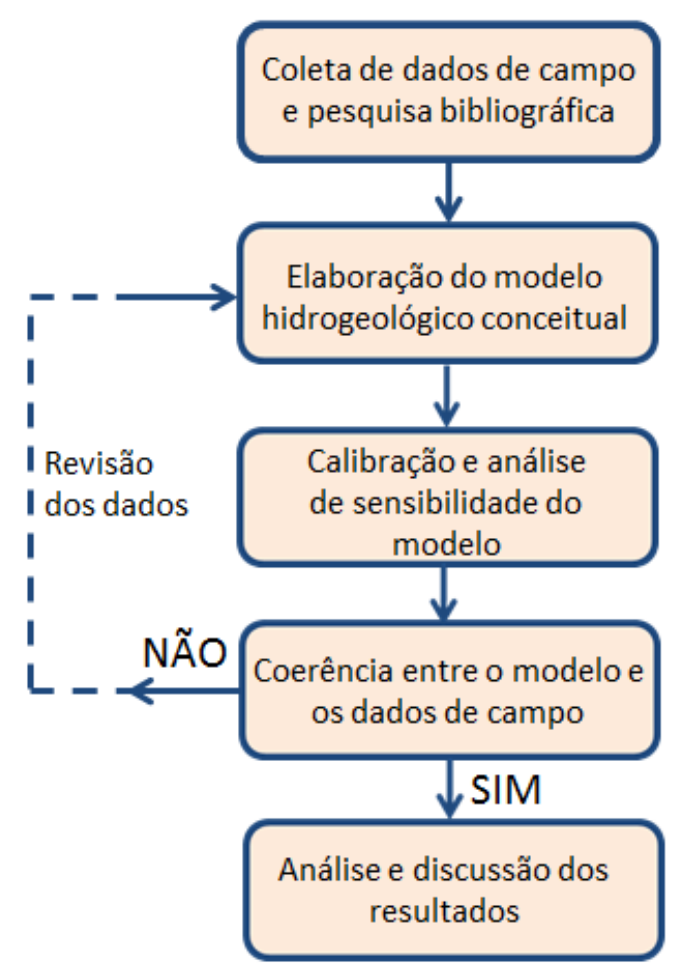

Figura 2 - Fluxograma da metodologia.

\section{1 - Área de Estudo}

A área de estudo em questão é chamada de "E85" com $85 \%$ v/v de etanol e $15 \%$ v/v de gasolina (Figura 3), a qual pertence ao REMA (Núcleo de pesquisas em Meio Ambiente) da Universidade Federal de Santa Catarina e está localizada em Florianópolis/SC com coordenadas (Datum Horizontal WGS84) S 27 30' / W 48 30' (Figura 4). A Fazenda ocupa uma área aproximada de $2.500 \mathrm{~m}^{2}$, com relevo plano (declividade entre 0 a $3 \%$ ), situada a $5,5 \mathrm{~m}$ de altitude em relação ao nível do mar. 


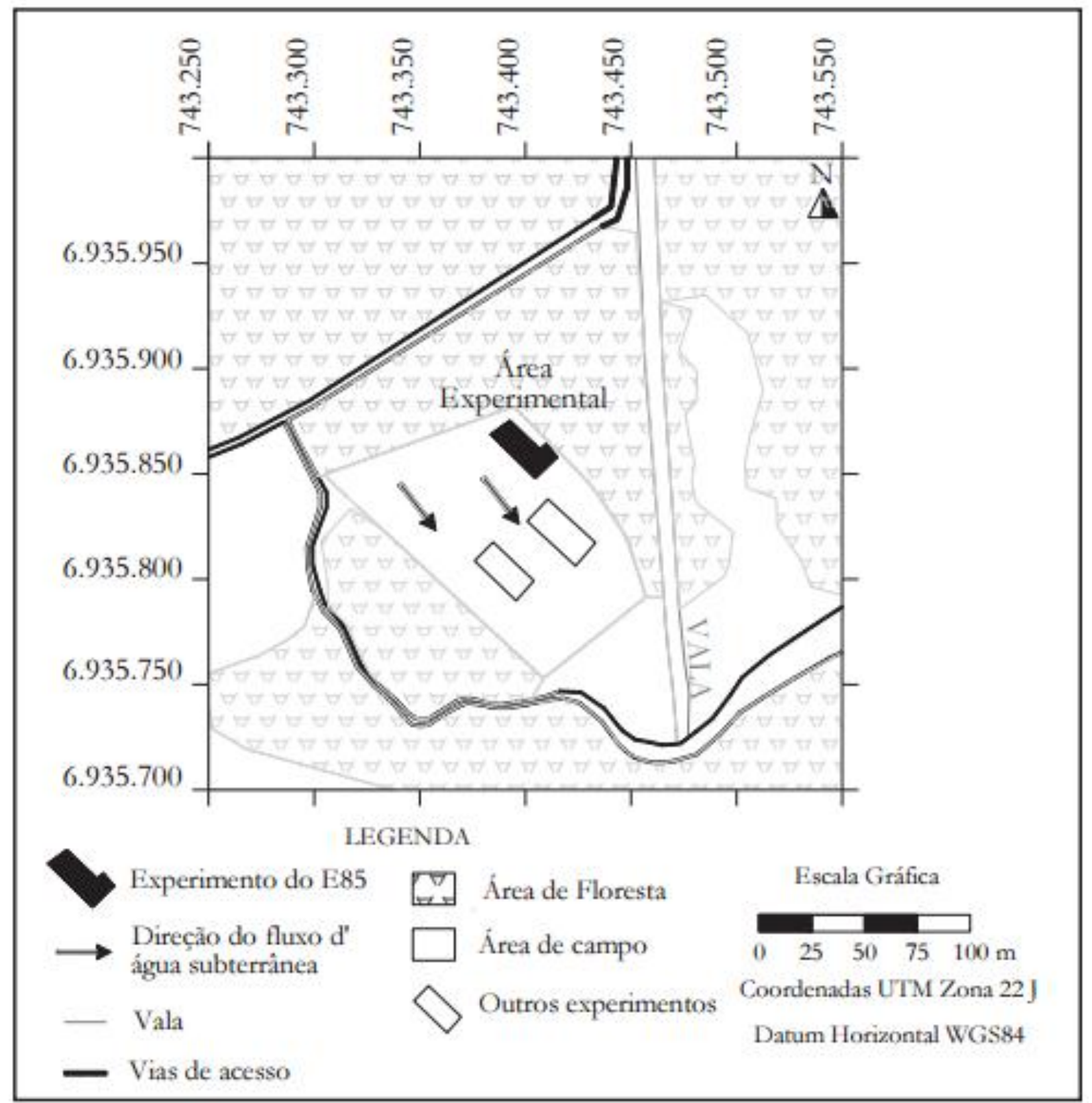

Figura 3 - Planta da área experimental e principais características do entorno. Fonte: FONSECA et. al, 2016. 
A)

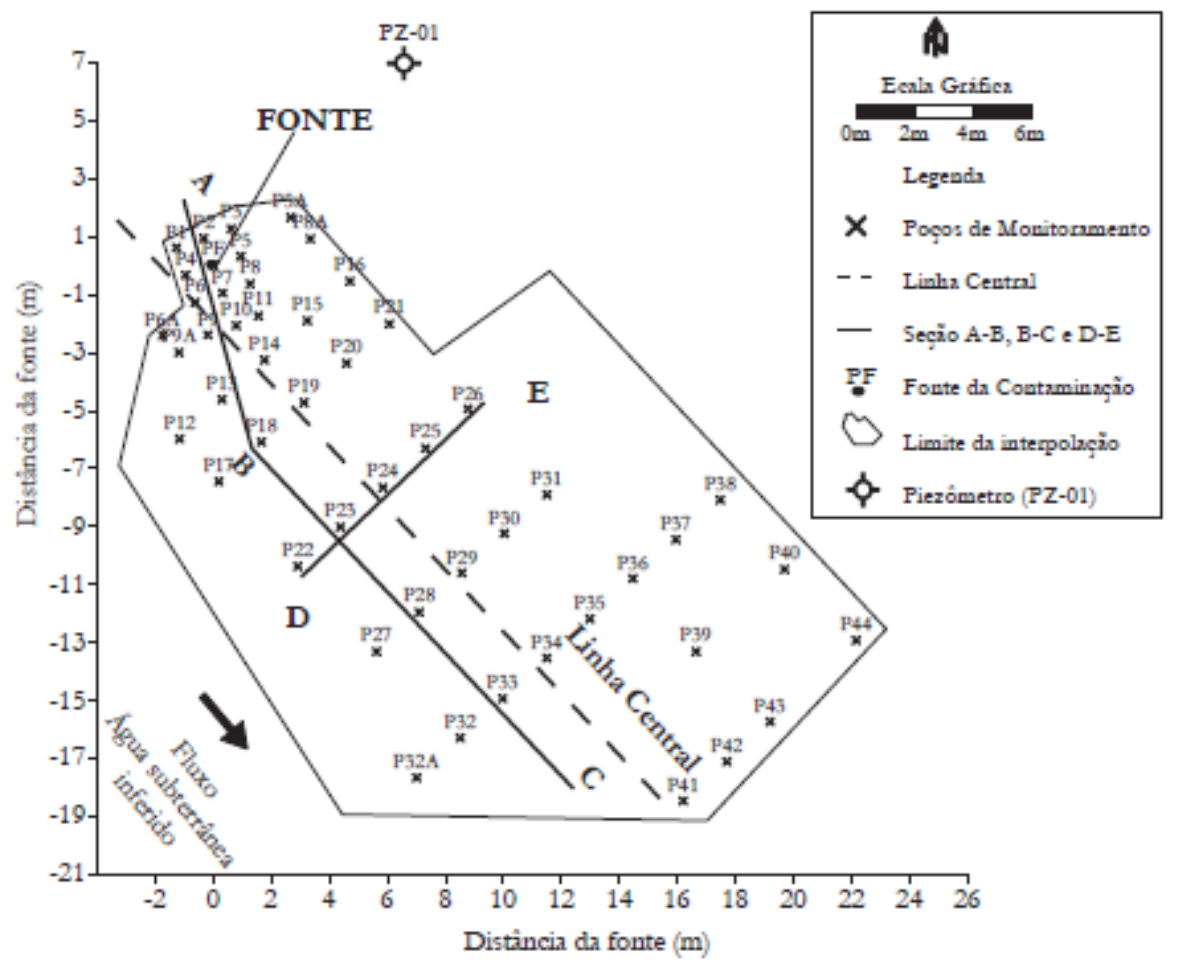

B)

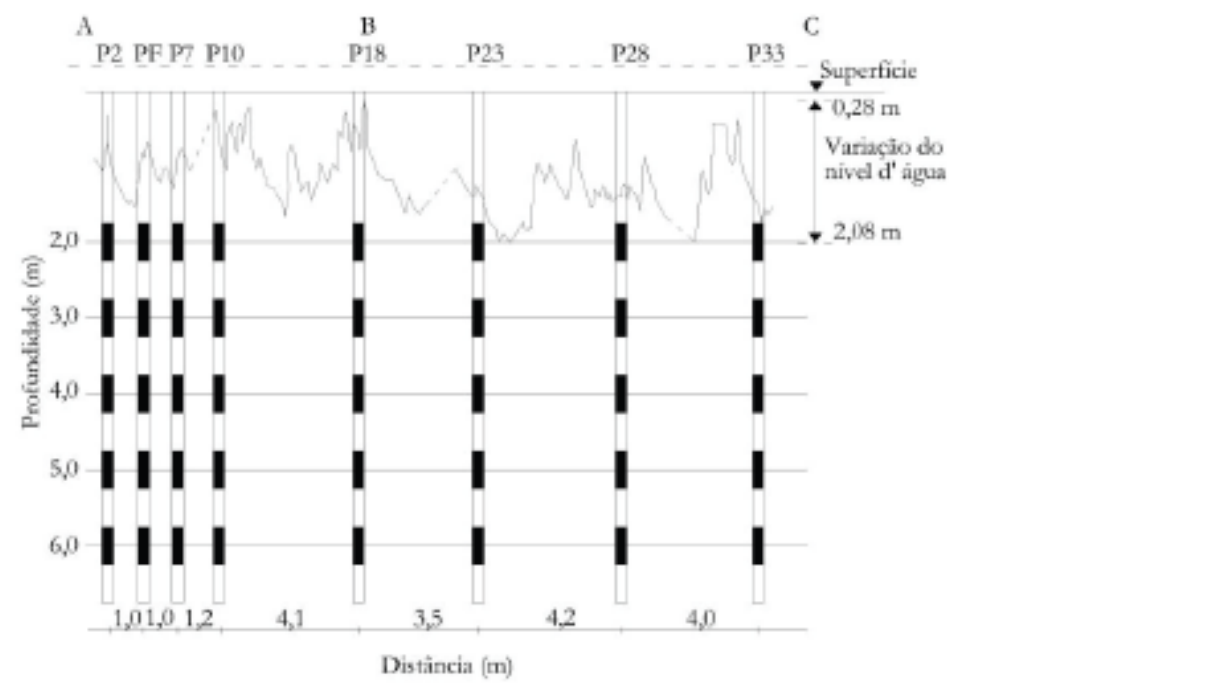

Figura 4 - Mapa da área experimental em planta (A), e seção vertical AB e BC (B). Na Figura 2A a distância dos eixos equivale à distância do poço fonte $(\mathrm{PF})$ considerado na posição $(0,0)$. A liberação do E85 ocorreu no entorno do PF. Fonte: FONSECA et. al, 2016.

Em setembro de 2010, foi liberada uma solução na zona não saturada do aquífero em uma fonte com dimensões de 1,0 $\mathrm{m}$ de comprimento, 1,5 $\mathrm{m}$ de largura e 0,25 $\mathrm{m}$ de profundidade, conforme a Figura 5. 


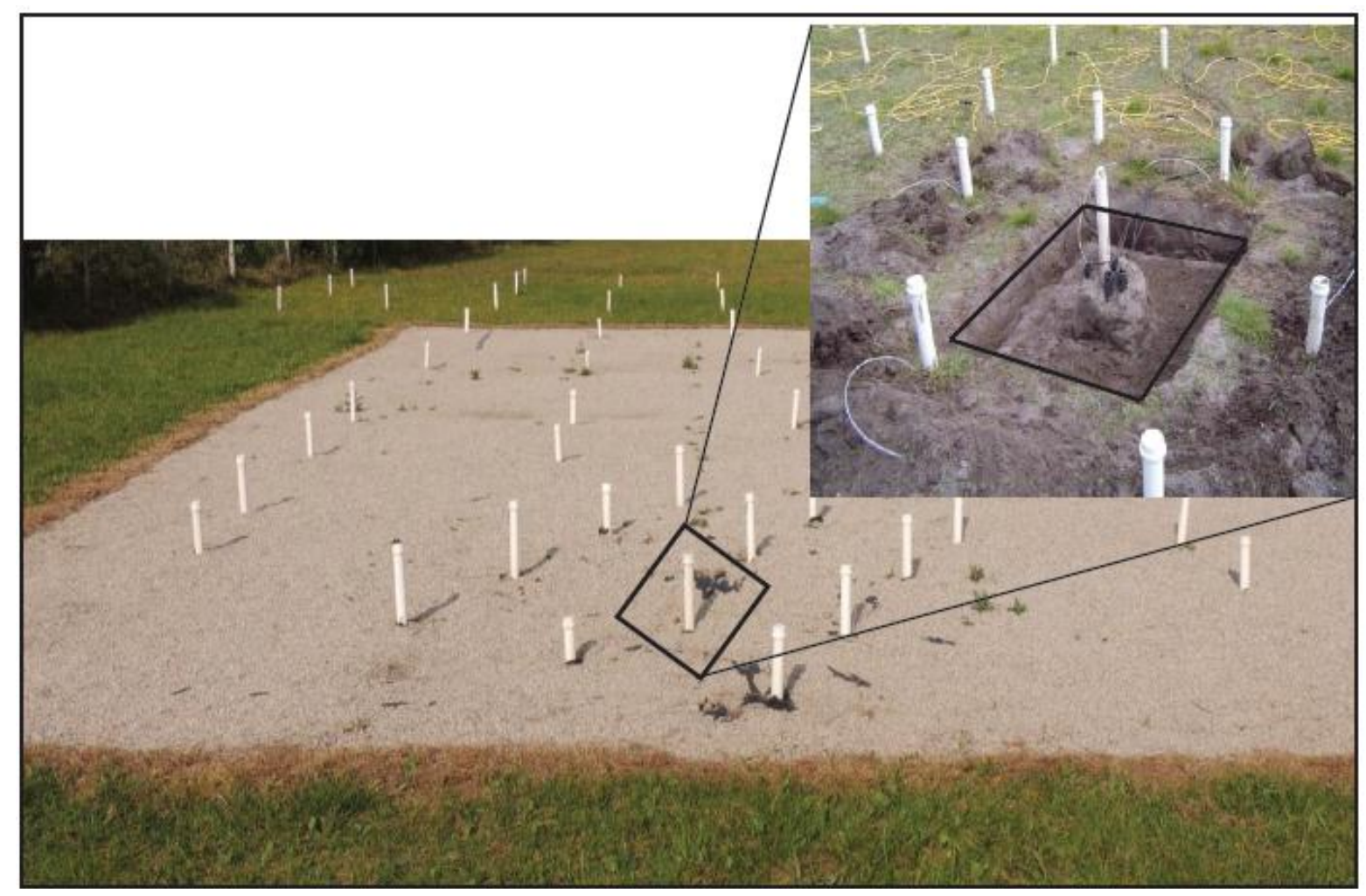

Figura 5 - Localização da área de liberação do E85 na área experimental. O detalhe demonstra a trincheira escavada no solo no entorno do poço fonte (PF) para liberação do E85 na zona não saturada. Fonte: FONSECA, et. al, 2016.

\section{4 - RESULTADOS ESPERADOS}

O comportamento do etanol em subsuperfície vem sendo estudado através de escala laboratorial e experimento de campo em derramamentos com misturas de combustíveis. Com este trabalho, espera-se que este comportamento também seja estudado através da modelagem. A partir da influência da precipitação, umidade do solo, influência no transporte de hidrocarbonetos na zona vadosa e comparação de resultados do modelo FEFLOW com experimentos em campo, deseja-se ser capaz de avaliar tal comportamento do etanol em uma mistura de combustíveis na zona vadosa. A identificação deste comportamento será importante para analisar estratégias de remediação e avaliação de passivos ambientais. 


\section{5- REFERÊNCIAS BIBLIOGRÁFICAS}

CETESB - Companhia Estadual de Tecnologia e Saneamento Ambiental de São Paulo. Importância das Águas Subterrâneas. São Paulo. 2014. Disponível em:

〈http://www.cetesb.sp.gov.br/agua/aguas-subterraneas/93-import\%C3\%A2ncia-das-\%C3\%A1guassubterr\%C3\%A2neas>. Acesso em: 14 out 2014.

DIAMANTINO, C; FERREIRA, J.P.L. Modelação da intrusão salina com o modelo matemático FEFLOW - fundamentos teóricos. $6^{\circ}$ Congresso da Água. Associação Portuguesa de Recursos Hídricos. 15 p. 2002.

FAGUNDES, J. R. T. Estudo integrado das características geológico-geotécnicas com vista à avaliação de recarga de aquífero : Região de São Carlos-SP. Tese de Doutorado. São Carlos/SP: Escola de Engenharia de São Carlos da Universidade de São Paulo/ Programa de Pós-Graduação e Área de concentração em geotecnia, 2010.

FONSECA, W.C; NUNES, C.C; FERNANDES, M; CORSEUIL, H.X. Impactos de derramamentos de etanol em água subterrânea - Experimento de campo. Revista Brasileira de Recursos Hídricos. Versão On-line ISSN 2318-0331RBRH vol. 21 no.1 Porto Alegre jan./mar. 2016 p. 105 - 117.

KOHNE J. M; KOHNE S; SIMUNEK, J. A review of model applications for structured soils: a) Water flow and tracer transport. Journal of Contaminant Hidrology. 2009, P 4-35.

TWARAKAVI, N.K.C; SIMUNEK, J; SEO, S. Evaluating Interactions between Groundwater and vadose zone Using the HYDRUS-based Flow Package for MODFLOW. Vadose Zone Journal. Vol. 7, No. 2, May 2008. 